\title{
O apoio institucional à migração massiva do ensino para o espaço digital em resposta à COVID-19
}

\author{
https://doi.org/10.21814/uminho.ed.24.7
}

\section{Manuel João Costa}

\begin{abstract}
Manuel João Costa (ORCID: 0000-0001-5255-4257) é Pró-Reitor dos Assuntos Estudantis e Inovação Pedagógica da Universidade do Minho. É bioquímico, professor da Escola de Medicina e investigador do Instituto de Investigação de Vida e Saúde (ICVS) da mesma Universidade. A sua atividade académica tem incidido sobre a inovação nas práticas pedagógicas no Ensino Superior e sobre a investigação da educação na área da saúde, em particular na educação médica, tendo participado na fundação do Centro de Inovação e Desenvolvimento do Ensino e da Aprendizagem na Universidade do Minho (Centro IDEA-UMINHO).
\end{abstract}


"Now is no time to think of what you do not have.

Think of what you can do with what there is".

Ernest Hemingway, O velho e o mar

Ensinar e aprender, até bem recentemente, pressupunham interaçóes face a face entre dois ou mais indivíduos num espaço físico partilhado. Independentemente do papel de cada indivíduo no processo, o de professor/a ou o de estudante, a imprescindibilidade do espaço físico era inquestionável. O espaço digital funcionava como um complemento do que acontecia presencialmente. Esta visão predominava na comunidade académica da Universidade do Minho nas vésperas da chegada da pandemia COVID-19.

Subitamente, a 10 de março de 2020, os espaços físicos de ensino e aprendizagem da Universidade do Minho foram interditados e vários locais de aprendizagem em contexto profissional - empresas, instituições de ensino ou saúde, ou outras - foram encerrados. Imperava a necessidade de proteger a saúde na academia e de suster a propagação da pandemia COVID-19. Professores e estudantes não se poderiam encontrar no mesmo espaço físico de ensino, sendo inesperadamente forçados a migrar para o espaço digital. O desafio repentino lançado à Universidade de reaprender a ensinar sem os seus espaços físicos foi sentido por toda a academia.

É agora consensual que a Universidade do Minho lidou adequadamente com as circunstâncias e foi bem-sucedida na forma como deu continuidade à sua missão formativa. Superando dificuldades sem precedentes, todos contribuíram para a agilidade com que a Universidade implementou mudanças profundas no seu ensino. Surgiram iniciativas para dotar os estudantes de dispositivos tecnológicos e para apoiar a migração digital das atividades dos estudantes e dos professores. Ensinar e aprender passaram a realizar-se com mediação tecnológica, com cada professor e cada estudante em espaços físicos distintos. Em duas semanas, foi migrada para o espaço digital a generalidade das atividades letivas que as circunstâncias permitiam manter em funcionamento.

Este texto é um contributo para compreender como a Universidade promoveu e apoiou a migração massiva do ensino para o espaço digital, suscitada pela pandemia 
COVID-19. Esta migração foi disruptiva, porém, paradoxalmente, criou oportunidades para uma transformação digital do ensino sem precedentes.

\section{O ENSINO NA UNIVERSIDADE DO MINHO ANTES DA COVID-19}

Quando encerraram os espaços letivos da Universidade, decorria a fase inicial do segundo semestre do ano letivo. As atividades e as avaliaçóes programadas para as unidades curriculares decorriam com normalidade, em regra presencialmente. As salas abriam-se diariamente. Todas as atividades letivas tinham horas agendadas para iniciar e para concluir. Os espaços destinados a atividades não letivas (corredores, salas de estudo, bares, bibliotecas, complexos desportivos, espaços exteriores, etc.) eram importantes espaços de socialização, de encontro com colegas nutrindo, assim, o sentido de pertença à academia. A informalidade nos espaços da Universidade contribuía para o bem-estar e para o fortalecimento da comunidade académica. A interrupção súbita e inesperada do ensino presencial alterou profundamente todos os aspetos da vida académica e o ensino com particular evidência. Uma profunda apreensão tomou conta da academia relativamente à continuidade das atividades letivas no restante semestre.

A Universidade disponibilizava a todas as unidades curriculares numa plataforma digital de ensino e aprendizagem, na qual estavam inscritos todos os estudantes. As funcionalidades da plataforma eram diversas, entre as quais a partilha de materiais, a comunicação ágil com os estudantes, atividades de discussão síncrona através da internet, fóruns de discussão e a realização de exercícios e testes. Porém, docentes e estudantes exploravam uma fração limitada das funcionalidades da plataforma, sendo as funcionalidades mais utilizadas o repositório de materiais, os registos de assiduidade e sumários e a comunicação entre os docentes e os seus estudantes. As funcionalidades que convocavam outras formas de interação (por exemplo, a lecionação de aulas no espaço digital) tinham menor utilização. A perspetiva do uso da plataforma como recurso central no desenvolvimento do ensino no espaço digital era território específico dos que se interessavam por modelos de ensino a distância.

A ação disruptiva da pandemia COVID-19 também foi sentida no apoio às atividades letivas e ao desenvolvimento e inovação no ensino, que funcionavam 
essencialmente num modelo presencial. O Gabinete de Apoio ao Ensino, a estrutura com a missão de suporte informático a toda a academia para fins educativos, atuava $\mathrm{e}$ era procurado presencialmente, embora disponibilizasse um serviço de apoio eletrónico para resolução de questóes e problemas no que concerne à prestação de apoio mais especializado, como por exemplo para apoiar os docentes na exploração das funcionalidades da plataforma. O Gabinete Para a Inclusão cuidava dos estudantes com necessidades especiais. Dispunha de um atendimento eletrónico em permanência, mas era presencialmente que realizava a sua atividade principal, designadamente as entrevistas de avaliação e de acompanhamento dos estudantes e as reuniôes de apoio e esclarecimento a estruturas das unidades orgânicas e a docentes. O Centro de Inovação e Desenvolvimento do Ensino e da Aprendizagem - Centro IDEA-UMinho - apoiava projetos de ensino presenciais e promovia anualmente iniciativas de formação pedagógica, também presenciais. No semestre em curso, estavam programados a segunda edição do retiro de formação pedagógica para docentes Docência+, a 2 $\underline{a}$ edição das Jornadas IDEA-UMinho para partilha de experiências pedagógicas e um evento internacional na área do ensino das ciências biomoleculares.

Subitamente, havia que reprogramar todas as operaçóes de ensino para que, mantendo os seus objetivos, pudessem funcionar integralmente no espaço digital. Apenas assim se criariam condiçóes para estimular e apoiar a academia na resposta sistémica que, sem aviso, fora forçada a dar.

\section{UMA RESPOSTA SISTÉMICA}

O plano geral de contingência da Universidade do Minho estabeleceu orientações concretas com os objetivos prioritários de frear a propagação da pandemia e de proteger a saúde da academia. Relativamente ao ensino, as orientaçóes para a resposta da Universidade estavam ainda em definição. Assim, impunha-se a necessidade de articular uma resposta sistémica, célere e amplamente participada, capaz de mitigar as enormes dificuldades da transição para o ensino online. Essa resposta desenvolveu-se com a coordenação central ao nível da Reitoria que procurou conduzir uma resposta sistémica da Universidade. Nesse sentido, uma medida importante que não cabe detalhar neste texto, consistiu num aumento da intensidade da articulação entre os órgãos 
e as estruturas da Universidade implicadas no ensino. A equipa reitoral, os presidentes das unidades orgânicas, os presidentes de conselhos pedagógicos e a Associação Académica da Universidade do Minho integraram os seus esforços para avaliar as necessidades no terreno, para definir as prioridades de intervenção e para concertar ações e medidas. Esta articulação adicionou coerência, pertinência e relevância à resposta da Universidade, conduzida por orientaçôes vertidas em despachos e circulares, que proporcionaram o devido enquadramento às adaptações mais profundas exigidas para o funcionamento do ensino.

É importante clarificar que as expetativas para o ensino decorrentes duma migração inesperada como esta não são comparáveis às colocadas em experiências de ensino a distância, pela impossibilidade de serem planeadas cuidadosamente. Hodges e seus colaboradores cunharam o termo "ensino remoto de emergência" para designar o processo de ensino-aprendizagem nas circunstâncias únicas desta pandemia ${ }^{1}$.

A evolução do ensino na Universidade do Minho, como resposta à pandemia, ajusta-se a um modelo geral de resposta das universidades de ensino presencial que optaram por uma transição massiva para o ensino remoto ${ }^{2}$. Tratou-se de um processo com fases distintas. Numa primeira fase, efetivou-se a transição propriamente dita das atividades de ensino. Nesta fase, prevaleceu o objetivo de dar continuidade, no mínimo tempo possível, digitalmente, ao que antes se vinha fazendo presencialmente. $\mathrm{O}$ investimento maior privilegiava a maximização das unidades curriculares migradas para o espaço digital, na expetativa de dar continuidade ao ensino e às aprendizagens para posteriormente, focar energias no modelo pedagógico das mesmas. Na segunda fase, assegurada a transição, procurou-se adaptar pedagogicamente as unidades curriculares às novas circunstâncias. Ganharam importância questóes como o aumento da participação dos estudantes online e o sucesso das aprendizagens, a equidade de acesso e de apoio nos processos de aprendizagem e ainda a conceção de processos alternativos de avaliação online que maximizassem a integridade académica. $\mathrm{O}$ modelo antecipou uma terceira fase para o início do primeiro semestre do ano letivo subsequente, pautada por

1Hodges, C., Moore, S., Lockee, B., Trust, T., \& Bond, A. (2020). The difference between emergency remote teaching and online learning. Educause Review, 27.

2 Phill Hill (2020). Revised Outlook for Higher Ed's Online Response to COVID-19. https://philonedtech. com/revised-outlook-for-higher-eds-online-response-to-COVID-19/. 
dificuldades na delineação de planos específicos para o ensino perante a incerteza sobre o que se venha a passar do ponto de vista epidemiológico. $\mathrm{Na}$ fase final, no pressuposto "novo normal", haverá mais previsibilidade da realidade epidemiológica, o que permitirá um planeamento mais ajustado e detalhado do ensino. A Universidade do Minho, que atravessou seguramente as duas primeiras fases, está a braços com a terceira, desde julho de 2020, no momento de escrita deste texto.

\section{A MIGRAÇÃO DIGITAL}

Até março de 2020, as atividades letivas expositivas de tipologia teórica, a discussão de conceitos, os esclarecimentos de dúvidas ou as provas de avaliação, eram asseguradas presencialmente. Já então havia disponibilidade de recursos tecnológicos que permitiam múltiplas formas de interaçôes digitais entre os professores e os estudantes, como por exemplo a realização de sessões de lecionação ou discussão, assim como formas alternativas de avaliação, tais como testes formativos com correção automática. A academia dispunha ainda do acesso a uma plataforma de reunióes virtual, que utilizava essencialmente em contextos de administração, gestão ou investigação.

No advento da pandemia COVID-19, impunha-se a urgência de aumentar massivamente as atividades no espaço digital. Registavam-se já algumas experiências do uso de recursos digitais no ensino, como a realização de testes na plataforma digital de ensino e aprendizagem ou o uso de sistemas de respostas para audiências (ARS Audience Response Systems) em sala de aula. Porém, as práticas dessa natureza estavam pouco disseminadas pela comunidade docente. Como tal, a obrigatoriedade de ensinar e aprender exclusivamente online suscitou uma inquietação generalizada. Num contexto de ensino presencial, tido como "normal", nem todos possuíam a confiança, a autonomia ou a devida competência digital. Os estudantes e os professores necessitavam de orientações e de apoio para o ensino poder ter continuidade. Realizadas as adaptações das infraestruturas tecnológicas para suportar a multiplicação de utilizadores que se antevia, disponibilizado o software e as licenças necessárias para maximizar a qualidade tecnológica das atividades, cabia à Universidade disponibilizar esse apoio. 
O apoio à migração envolveu de forma direta e em todas as fases o Gabinete de Apoio ao Ensino (GAE) e o Centro de Inovação e Desenvolvimento do Ensino e da Aprendizagem (IDEA-UMinho). A coerência e a complementaridade de áreas de atuação destas estruturas foram chave para produzir recursos, ações de formação e outras iniciativas, com a prontidão necessária para atender às necessidades reais da Universidade do Minho. As atividades do GAE incidiram na introdução e apoio à utilização das ferramentas e recursos tecnológicos, designadamente no apoio à utilização proficiente dos recursos digitais de suporte e de mediação da atividade docente. O Centro IDEA-UMinho focou-se no desenvolvimento pedagógico dos docentes e ainda na criação de espaços informais que mantivessem o sentimento de vinculação de docentes e de estudantes a uma comunidade académica que se queria manter apesar da separação física dos seus membros.

\section{APOIO À ADOÇÃO DE FERRAMENTAS TECNOLÓGICAS NO ENSINO: O GABINETE DE APOIO AO ENSINO}

Com o intuito de mitigar os desafios tecnológicos criados pela impossibilidade de ministrar aulas e de realizar avaliaçóes presenciais, o Gabinete de Apoio ao Ensino $(G A E)$ compilou e disponibilizou na sua página de internet várias ferramentas, tutoriais e manuais de apoio à adoção de tecnologias para mediar o ensino e a avaliação. A disponibilização de ferramentas foi acompanhada pela realização de sessóes online de esclarecimento e de apoio ao uso das soluçôes, acessíveis a partir da página internet do GAE e divulgadas eletronicamente nos canais da Universidade. Estas sessões realizaram-se a um ritmo considerável e inaudito até ao momento. Entre março e julho de 2020, realizaram-se 233 sessões de apoio e formação que registaram um total de 1336 participaçóes. Complementarmente, o GAE atendeu a solicitaçóes de unidades orgânicas para a realização de sessões de formação particularizadas. No que respeita às soluções para a avaliação das aprendizagens online, incluíram-se ainda recursos para apoiar os estudantes na sua preparação e realização de avaliaçốes online.

A cronologia da disponibilização das soluçóes acompanhou a premência dos diferentes tipos de necessidades em cada momento. Assim, o foco inicial foi a produção de materiais de apoio para a lecionação online. Produziram-se recomendaçôes e vídeos 
demonstrativos sobre como conceber uma apresentação narrada e como disponibilizá-la online ou sobre como dinamizar aulas online utilizando ferramentas concebidas para realizar reunióes. Ainda numa fase inicial, perante a necessidade de agilizar o esclarecimento de questóes relacionadas com a proteção de dados, aquando da gravação das sessóes síncronas, foi disponibilizado um sumário das orientaçốes consonantes com o Regulamento Geral de Proteção de Dados. Estas ações contribuíram para agilizar a migração digital das atividades letivas.

Subsequentemente, produziram-se recursos de apoio à realização de avaliação online através da plataforma digital de ensino e aprendizagem da Universidade. Por exemplo, disponibilizaram-se guiões para a submissão de trabalhos dos estudantes com análise de plágio, para a produção e a realização de testes online, para a gestão de pautas e a interpretação de análises da qualidade dos testes produzidas pela plataforma, ou para a realização de avaliação por pares. Tendo em consideração que a realização de avaliaçôes online seria igualmente desafiante para os estudantes, produziram-se materiais, incluindo uma nova área na página de internet destinada a apoiar os estudantes na preparação para provas de avaliação sumativas online. Essa área incluiu recomendações relativas a como preparar-se para uma prova, como organizar o espaço físico para assegurar as melhores condiçôes técnicas, precavendo a captação e difusão de elementos sensíveis do ponto de vista da privacidade, uma lista de pontos a verificar antes duma prova, elementos para a organização no dia da prova e sobre como lidar com dificuldades inesperadas surgidas no decorrer da prova.

Associada às dúvidas sobre as soluções tecnológicas para avaliar online, a academia denotou particular preocupação com as consequências para a integridade académica de avaliar online. Além da atenção a este tema pelo Centro IDEA-UMinho, o $G A E$ deu um contributo relevante no estudo de impacto da ferramenta de vigilância de exames remotos que viria a ser adotada na Universidade. Como nas fases anteriores, o $G A E$ desenvolveu recursos de apoio e promoveu sessóes online de esclarecimento sobre a utilização da nova ferramenta.

A relevância das ferramentas propostas e a acessibilidade a apoio por parte deste gabinete terão contribuído para o ritmo com que evoluiu a generalização da adoção das ferramentas digitais e, por conseguinte, para o sucesso da resposta sistémica da 
Universidade. A utilização dos recursos propostos aumentou expressivamente em relação ao mês anterior e também em relação a igual período do ano letivo anterior (ver abaixo). A acessibilidade a estes recursos e o apoio à sua adoção terá mitigado algumas dificuldades tecnológicas de docentes e de estudantes, criando assim condiçóes para um foco no processo de ensino e aprendizagem.

\section{APOIO AO DESENVOLVIMENTO DE ABORDAGENS AO ENSINO ONLINE: CENTRO IDEA}

As ações do Centro IDEA-UMinho incidiram sobre a formação dos docentes, tendo em vista a adaptação dos processos de ensino e aprendizagem com recurso às tecnologias digitais e ainda a promoção da partilha de experiências entre docentes. $\mathrm{O}$ centro produziu materiais, disseminou recursos e promoveu iniciativas diversas, no que veio a constituir uma nova dimensão de atuação, designada IDEA Digital ${ }^{3}$. O IDEA Digital e as iniciativas promovidas pelo $G A E$ foram articuladas, o que permitiu concertar o apoio à seleção com o apoio à aplicação pedagógica das soluçóes tecnológicas. $\mathrm{O}$ uso das redes sociais (designadamente o Facebook e o Twitter) constituiu um aspeto fundamental do IDEA Digital, ampliando o seu alcance e agilizando a disseminação das iniciativas e dos recursos produzidos.

As iniciativas IDEA Digital encontram-se caraterizadas sucintamente no quadro 1. As iniciativas propostas tinham a intenção de disseminar práticas relevantes, focadas e potencialmente úteis para a generalidade dos docentes da Universidade. O IDEA Digital procurou reunir a academia em torno das novas questóes do ensino remoto de emergência, promover a difusão de boas práticas externas à Universidade e dinamizar internamente a partilha de boas experiências que surgiram dentro dela . Por exemplo, ao nível da difusão de boas práticas, publicaram-se os boletins "IDEA Digital". Estes boletins temáticos, com a extensão máxima de uma folha $\mathrm{A} 4$, resumiram boas práticas por forma a proporcionar aos docentes uma fonte de informação acessível e segura que fornecia respostas a questóes do seu dia-a-dia. No que concerne ao desenvolvimento e à realização de sessóes formativas, criou-se um modelo de formação invertido - os flipped

3 https://idea.uminho.pt/pt/ideadigital. 
webinars - e transformou-se o retiro de formação Docência +, programado presencialmente para julho, numa iniciativa de formação a distância. Além disso, procurando soluções digitais para certificação das suas ações de formação, implementou-se o uso de microcredenciais digitais (open badges). Por último, convidaram-se especialistas internacionais para realizar webinars sobre temas relacionados com a migração para o ensino online. Um outro texto da presente coletânea descreve com maior detalhe e apresenta os resultados do impacto de todas a iniciativas que compuseram o IDEA Digital ${ }^{4}$. Seguidamente, descrevem-se de forma resumida as duas iniciativas com impacto mais expressivo.

Quadro 1. Descrição sucinta das iniciativas IDEA Digital.

Boletins IDEA-Digital Resumos de literatura e de recomendações relativas a aspetos específicos de ensinar, aprender e avaliar online com sugestôes de operacionalização.

Webinars por

peritos externos

Flipped Webinars

Docênciat online

Partilhando IDEiAs
Webinars temáticos proferidos por convidados externos com perguntas e respostas.

Sessões de formação síncronas com a duração máxima de 60 minutos, destinadas a docentes que pretendam aprender sobre como implementar um recurso tecnológico específico ou uma metodologia nas suas aulas; os dinamizadores foram colegas que usam essas tecnologias ou metodologias.

Iniciativa de formação destinada aos docentes, com foco nos processos de ensino e aprendizagem digitais, reflexão e transformação das suas unidades curriculares, com acompanhamento de um grupo de facilitadores, docentes e estudantes. A carga horária foi de vinte horas.

Sessões síncronas abertas a toda a academia e docentes externos, para a troca informal de experiências entre os participantes sobre os temas subjacentes.

4 Ver o texto 'O papel do Centro IDEA-UMinho na transição para o ensino online durante a pandemia COVID-19: enfrentar desafios e criar oportunidades', da autoria de Gabriel Gerber Hornink, Flávia Vieira e Manuel João Costa. 
Facebook e Twitter Canais para divulgação das produções e eventos relacionados com o ensino digital; adicionalmente foram canais céleres de comunicação e de envolvimento de colegas interessados nas temáticas.

Certificação por Aplicação de um sistema de microcredenciais digitais (open badges) de certiopen badges ficação dos envolvidos nas ações de formação.

\section{PARTILHANDO IDEiAs}

Em tempos de distanciamento, emergiu uma necessidade de manter a academia em contato e de preencher o espaço deixado em aberto pela ausência de espaços regulares e informais de encontro. Foi sob este desígnio que nasceu a iniciativa Partibando IDEiAs, que consistiu em sessóes semanais de partilha de experiências e de dificuldades num espaço virtual. Abriram-se as sessóes à participação de toda a academia. Cada sessão desenrolou-se com um tema de fundo, difundido previamente. Os temas ora convidavam à partilha de práticas - por exemplo, sobre "A estruturação da avaliação à distância"- ou à reflexão coletiva sobre desafios - por exemplo "O ensino na Universidade do Minho em 2021: como preparar?”. Ocasionalmente, envolveram convidados que trouxeram perspetivas institucionais, como foi o caso da última sessão, que contou com a presença dos Reitores das universidades do Minho e de Aveiro, para debater "O futuro próximo do nosso ensino superior”. Após introdução ao tema da sessão, os participantes eram em regra distribuídos por salas virtuais, em grupos de 10 a 15 participantes, cabendo a mediadores da equipa de organização da sessão o papel de resumir as principais ideias num momento final de discussão em plenário. As sessóes foram agendadas para o final da tarde do mesmo dia da semana e para a mesma hora. Sinalizava-se assim a possibilidade de um espaço regular, embora digital, para todos poderem partilhar dificuldades, mas também soluçóes. Participaram estudantes, docentes e funcionários da Universidade e também houve inscritos de outras instituiçôes. A iniciativa veio a constituir-se como um ponto de encontro para a academia, tendo tido uma participação média próxima da centena de indivíduos ao longo de doze sessóes ininterruptas. 


\section{DOCÊNCIA+}

Em 2019, tinha tido lugar a primeira iniciativa Docênciat, uma formação pedagógica intensiva em formato de retiro presencial, oferecida a 80 participantes. Em 2020, estava programada a segunda edição em moldes idênticos. Como consequência da pandemia, a formação Docência + foi organizada em modelo remoto pela Universidade do Minho e pela Universidade de Aveiro. O objetivo principal da iniciativa foi redefinido, passando a incluir a capacitação dos participantes para os processos de ensino e aprendizagem em modelos que combinam momentos presenciais com momentos de aprendizagem remota. A formação decorreu em julho de 2020, com 200 participantes, 100 de cada instituição. Os participantes foram desafiados a desenvolver um plano que reformulasse uma unidade curricular em que estivessem ou viessem a estar envolvidos, com o apoio de equipas de "facilitadores" que integravam docentes e estudantes. A formação foi desenhada com momentos de trabalho síncrono e assíncrono, num total de cerca de 20 horas. Foi estruturada em módulos com os temas "Como preparar uma UC em modelo blended learning", "Como usar as tecnologias e metodologias em contexto letivo" "Como avaliar as aprendizagens" e "Como avaliar o funcionamento de unidades curriculares tendo em conta a sua melhoria contínua”. Esta edição do Docência+ terminou com um balanço muito positivo por parte dos participantes, facilitadores e organizadores, ficando agendada uma nova edição para setembro de 2020.

\section{OS NOVOS DESAFIOS: ACESSO E VULNERABILIDADES DIGITAIS}

Estar presente no mundo digital exige aos utilizadores a disponibilidade de dispositivos e de infraestruturas de comunicação. Quando as circunstâncias obrigaram à migração do ensino para o espaço digital, nem todos na academia minhota dispunham das condições tecnológicas necessárias para o fazer. A desigualdade de condições de acesso ao mundo digital é referida como digital divide ${ }^{5}$ e divide os indivíduos entre os que conseguem e os que não conseguem aceder aos recursos de aprendizagem online. Pode, por conseguinte, ser fraturante. Nos momentos iniciais da resposta à pandemia, tornou-se evidente que alguns estudantes se debatiam com a indisponibilidade de

5 https://en.wikipedia.org/wiki/Digital divide\#cite note-NTIA95-1. 
equipamentos ou de acesso a rede de qualidade suficiente para poderem participar nas atividades letivas. Isso configurava um risco de ver estudantes ser excluídos do processo de aprendizagem.

Para responder eficazmente a ambas as circunstâncias, a Universidade desenvolveu, através dos Serviços de Ação Social, um programa de apoio para permitir aos estudantes o acesso rápido a equipamentos informáticos por empréstimo. O programa disponibilizou computadores, dispositivos audiovisuais e cartôes de internet móvel. Os estudantes carenciados economicamente, que não tinham possibilidade de acesso ao ensino remoto, puderam candidatar-se a este apoio informático temporário. Em articulação com a Associação Académica da Universidade do Minho foi organizada uma campanha de solidariedade junto de empresas da área e de antigos alunos, que recolheu vários equipamentos por doação. Paralelamente, mobilizou dispositivos portáteis temporariamente disponíveis na Universidade pelo facto de não decorrerem atividades presenciais. Foi possível dar resposta positiva à totalidade das solicitaçóes que cumpriam os critérios de elegibilidade.

Tão importante como o acesso ao ensino digital são as questóes da equidade e da inclusão. As dificuldades de acesso de professores ou estudantes ao ensino no mundo digital, podem estar sobretudo relacionadas com uma menor adaptabilidade e/ou experiência com o mundo digital ${ }^{6}$, traduzida em termos como 'habilidades digitais', 'literacia digital', 'competência digital', 'confiança digital', 'autonomia digital' ou 'responsabilidade digital'. A migração inesperada do ensino para o mundo digital poderá ter suscitado novas vulnerabilidades, decorrentes, por exemplo de uma menor capacidade de usar as plataformas digitais ou de comunicar por meio de ferramentas digitais. Num universo de cerca de vinte mil estudantes, é expectável existirem indivíduos com maiores dificuldades nos processos digitais e, portanto, mais vulneráveis no que concerne ao potencial sucesso das aprendizagens. Dar resposta a esta vulnerabilidade foi e permanece particularmente desafiante, perante a inexequibilidade dum cenário de apoio personalizado a cada indivíduo e ainda perante a necessidade de compromisso dos próprios indivíduos para evoluir na sua capacidade de utilização das tecnologias.

6 Nambisan, S., Lyytinen, K., Majchrzak, A., \& Song, M. (2017). Digital Innovation Management: Reinventing innovation management research in a digital world. Mis Quarterly, 41(1). 
Para minorar esta dificuldade os boletins IDEA DIGITAL ofereceram sugestões concretas e o tema da equidade no espaço digital foi integrado na iniciativa Docênciat. A mitigação de vulnerabilidades decorrentes de dificuldades relacionadas com o acesso ou uso de tecnologias digitais exige um compromisso permanente de toda a comunidade académica que deve ser reforçado para o futuro.

\section{A MIGRAÇÃO: ALGUNS NÚMEROS}

Num espaço de duas semanas após o encerramento das instalaçóes dos campi da Universidade do Minho, um número considerável de docentes lecionava as suas aulas online ou disponibilizava registos gravados das mesmas na plataforma digital de ensino e aprendizagem. A utilização contrastava claramente com a que se verificava em 2019, embora os recursos já estivessem disponíveis nesse período. Os números que se seguem atestam da capacidade que houve em migrar as atividades para o espaço digital.

Em 2019, no período entre março e junho, a percentagem de unidades curriculares existentes na plataforma que utilizava as ferramentas de comunicação e colaboração (testes, trabalhos, diário, fórum e blogue, sendo as mais utilizadas os testes e trabalhos) cifrava-se em 11.2\%. Em 2020, no mesmo período, esse número era de 44.2\%. A ferramenta de videoconferência, Blackboard Collaborate Ultra, utilizada muito residualmente em 2019, no período de março a junho de 2020 apresentou 74.105 sessóes, num máximo de 186 sessôes em simultâneo. Estas sessóes contaram com 515.696 participantes. Comparando os meses de janeiro e fevereiro de 2020, que comportaram uma média de 550 sessóes, março atingiu as 20.550 e este número manteve-se até junho, na época de exames. Nos meses de março, abril e maio, registaram-se médias de mais de 2.000 utilizadores em simultâneo.

Paralelamente, houve um aumento expressivo de utilização da plataforma Colibri-Zoom. Assim, as médias dos meses de janeiro e fevereiro relativamente ao número de sessões realizadas eram de 175 e de 812 relativamente ao número de participantes nas reuniôes. Relativamente às mesmas médias entre março e junho, esses valores eram respetivamente 9.435 e 10.9536, traduzindo um aumento de utilização aproximado 
de 54 e de 135 vezes. No que concerne ao total médio de minutos acumulados, os valores subiram de 60.251 para 7.432.115, ou seja, aumentaram 123 vezes.

\section{CONCLUSÃO}

A migração do ensino para o espaço digital foi um acontecimento sem precedentes na Universidade do Minho, tal como o foi em múltiplas instituições por todo o mundo. Os docentes e os estudantes, a maioria com experiência limitada no ensino à distância, debateram-se com necessidades fundamentais relacionadas com as formas de ensinar e de aprender no espaço digital. O imediatismo da necessidade de migrar rápida e massivamente todo o ensino não permitiu um planeamento atempado, deixando à Universidade o difícil desafio de se recriar no que veio a ser designado "ensino remoto de emergência.” A Universidade reagiu coletivamente com o envolvimento das suas estruturas de apoio ao ensino, também elas reinventadas como consequência da pandemia. Como consequência houve continuidade do ensino na Universidade do Minho. No final do ano letivo, as próprias estruturas de apoio sofreram uma transformação digital, estando melhor preparadas para prosseguir a sua missão nos tempos de maior ou menor incerteza que se seguirão. Dispor de estruturas de apoio ao ensino competentes dos pontos de vista tecnológico e pedagógico foi importante para encontrar e explorar oportunidades num momento tão disruptivo como o desta pandemia.

A experiência vivida demonstrou uma enorme disponibilidade de professores e de estudantes para a reinvenção do ensino na Universidade do Minho. Esta capacidade dá tranquilidade e confiança para enfrentar as incertezas do futuro. 